\title{
Effects of surfactant on bubble size distribution and gas hold-up in a bubble column
}

\author{
Maedeh Asari ${ }^{1}$, Faramarz Hormozi ${ }^{2}$ * \\ ${ }^{1}$ Faculty of Engineering- Dempartment of Chemical Engineering, Islamic Azad University, Shahrood Branch, Shahrood, Iran \\ ${ }^{2}$ Faculty of Chemical, Gas and Petroleum Engineering, Semnan University, Semnan, Iran
}

Email address:

Maedeh_asari@yahoo.com(M. Asari),fhormozi@semnan.ac.ir(F. Hormozi)

To cite this article:

Maedeh Asari, Faramarz Hormozi. Effects of Surfactant on Bubble Size Distribution and Gas Hold-up in a Bubble Column. American Journal of Chemical Engineering, Vol. 1, No. 2, 2013, pp. 50-58. doi: 10.11648/j.ajche.20130102.14

\begin{abstract}
This study investigates the influence of two surfactants -a non-ionic (Tween20) and a zwitterionic (Cocoamidopropyl Betaine) - upon the gas-liquid hydrodynamics in a bubble column. These kinds of substances can have an important influence upon the gas-liquid hydrodynamics, specifically on the bubble size and gas hold-up. Bubble diameters were measured photographically in a bubble column, which was operating in the homogeneous regime with air and aqueous surfactant solutions. The bubble size and gas hold-up data were determined for several values of the superficial gas velocity $(0.13,0.26$ and $0.5 \mathrm{~cm} / \mathrm{s})$. On the other hand, bubble diameter was determined for different values of surfactant concentration $(0.02,0.05$ and $0.1 \% \mathrm{vol})$. At superficial gas velocity below $0.26 \mathrm{~cm} / \mathrm{s}$, addition of surfactant in air-water has low influence on bubble size, whereas higher gas velocity addition of surfactant increases the number of bubble. In surfactant solutions (in comparison with pour water), resulted in an increase in number of bubble and a rough decrease in Sauter mean bubble diameter. Bubbles tend to become smaller with decreasing surface tension of water. Therefore, surfactant existence increases the gas hold-up. Further, gas holdup increased when gas bubbles movement increased.
\end{abstract}

Keyword: Bubble Column, Surfactant, Bubble Size, Gas Hold-Up

\section{Introduction}

Bubble columns have found their wide application in biochemical processing industries due to their simple construction, low cost and ease of operation. These devices are intensively utilized as multiphase contactors and reactors in chemical, petrochemical and biochemical industries [6]. About $30 \%$ of all chemical processes occur between a gas phase and a liquid phase [8] such as oxidation of ethylene to acetaldehyde, oxidation of wet air, synthesis of methanol in liquid phases, synthesis FisherTrabs, hydrogenation of maleic acid, bacteria culture, parasite of fungus culture, production of single-cell protein, culture of animal cells and wastewater treatment [20]. Bubble columns are characterized by large liquid phase hold-up which makes them attractive reactors for kinetically slow gas-liquid reactions [3]. Surfactants are the materials consisting of molecules which contain both polar and non-polar parts (amphiphilic). In the aqueous phase, the hydrophobic hydrocarbon chains to escape from water phase[26]. Surfactants, both chemical and biological, can reduce surface and interfacial by accumulating at the interface of immiscible fluids and increasing the solubility, mobility, bioavailability and subsequent biodegradation of hydrophobic or insoluble organic compounds [6]. These materials are widely used as antifoam agent, wetting agent, detergent, film coating, emulsifying agent, chemical and petrochemical productions [21]. The size of the bubble in bubble column depends on the sparger, superficial gas velocity, and concentration of liquid phase [3]. There are several other techniques for determination of bubble size in bubble column that involve light scattering, light reflection and depolarization and optical probes [4]. The simplest characterization method is the photographic approach, which has been widely used. The effect of gas flow rates on bubble size was investigated by Akita and Yoshida [2] and the result showed a decrease in bubble size with increasing 
gas flow rate. Krishna and Krishna [18] reported that in the heterogeneous regime the mass transfer was significantly enhanced by the continuous bubble break-up and coalescence tendencies. Kalekar et al.[16] investigated the adsorption of various surfactants at gas-liquid interface. Kothekar et al. [17] studied the foam stability, surface tension and interfacial tension of Tween 20, Tween 60 and Tween 80. Bubble diameter reduction and oxygen concentration in some systems containing different surfactants were reported in the literature [25]. Garcia et al. [13] investigated Tween 80 in silicon oil + water solution decreased bubble diameter. Anastasiou et al.[5] reported that the bubble size in Triton X-100 /water system is smaller than SDS/water system on bubble column and the effect of surfactant additives on gas hold-up in the pseudohomogeneous has also been studied. Yang and maa [27] studied ionic surfactants (SDS, SDBS) in water systems and showed that the coalescence time increased with increasing surfactant concentration. Fractional gas hold-up is an important parameter in the design and scale-up of gasliquid dispersion. It has several direct and indirect influences on the column performance. The gas hold-up generally increases when a surfactant of either kind is present in bubble column [24]. Bouaifi et al.[7] studied the gas hold-up, interfacial area, the bubble size, and bubble distribution in two gas-liquid dispersion columns. Most of the results on gas hold-up are in the form of a plethora of empirical correlations, collected and discussed in reference books[11], and review papers[ 15,23]. In this research, bubble size distribution and gas hold-up in bubble column reactor were investigated when different surfactants (containing Tween 20, Betaine) at various concentrations were added into the water. The effect of superficial gas velocity on the bubble diameter and gas hold-up were studied.

\section{Experiments and Methods}

\section{1. Experimental Setup}

Schematic diagram of the experimental setup is shown in Fig. 1. And it consists of small vertical rectangular Plexiglas column (with height of $1.2 \mathrm{~m}$, width of $0.2 \mathrm{~m}$ and depth of $0.05 \mathrm{~m}$ ). The column is equipped with appropriate flow meter for gas phase flow measurement and control. During the experiments, the gas was injected through a gas distribution. The gas distribution sparger was an orifice with injector. The gas distribution located at the bottom of the column with $1.2 \mathrm{~mm}$ in diameter made of the Plexiglas. Air was supplied with a regulated pressure pump. The gasfree liquid height in the column for each experiment was about $0.45 \mathrm{~m}$. The gas flow was then stopped in order to begin each experimental run. . The bubble diameter size was determined with a photographic technique by a digital camera (CASIO EXILIM, model: EX-F1 with resolution of $8 \mathrm{M}$ pixels). To determine profiles of ellipsoid bubble, camera distance of column was 1 meter. The camera was located perpendicular to the surface for photography. The light was shone on the other side of the column that was in front of the camera. It is better to use cool light and smooth light, but it is also with other types of lights. In the present work two halogen lamps with a consumption power $1 \mathrm{KW}$ were used. For uniformity of lights a paper [1] or white screen [28] that located between light and bubble column was used. In this study, a opaque plate of Plexiglas was used. When the light was shone in back of column, It was reflected because of the collision of the light with bubble and the part of the light did not arrive to the camera. This part in photos was dark and created a boundary for bubbles that lead to better diagnosis in photos. All the experiments were carried out at ambient conditions (atmospheric pressure $25( \pm 0.5) \square \mathrm{C})$.

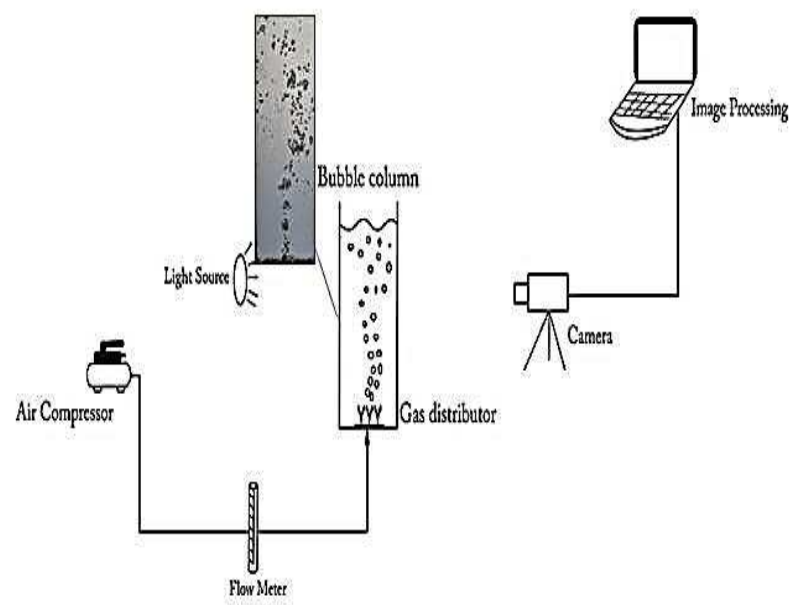

Fig 1. Schematic diagram of the experimental set-up

\section{2. Materials}

Tween 20 ((Polysorbate 20), [CAS no: 9005-64-5]) and Betaine ((Cocoamidopropyl betaine), [CAS no: 61789-40-0]) were purchased from Merck Company (Germany) and their various solutions with various concentrations were prepared. The properties of these surfactants are shown in detail in Table 1. Distilled water was utilized in the experiments. Air from column was used as the sparging gas. The diameters of the bubbles were determined from photographs the operating column, $40 \mathrm{~cm}, 20 \mathrm{~m}$ and $5 \mathrm{~cm}$ away from gas distributor. The dimensions of the bubbles, which were supposed to be ellipsoids, were measured directly from the photographs. Among 50 to 1000 bubbles were measured at each experimental point, using 27-30 photographs. Fig.2. illustrates examples of the of bubbles in Tween 20 in water system $\left(\mathrm{u}_{\mathrm{g}}=0.13,0.26\right.$ and $\left.0.5 \mathrm{~cm} / \mathrm{s}\right)$ at $\mathrm{C}_{\mathrm{s}}=0.02 \%$ vol. Major (a) and minor (b) axes of the projected ellipsoid were measured and the diameter of the volume-equivalent was taken as the representative bubble dimension [13].

\section{3. Methods}

$$
d=\sqrt[3]{a^{2} b}
$$

Eq. (2) is used to determine the bubble area 


$$
A=\frac{\pi a b}{4}
$$

and bubble eccentricity is calculated from the following equation:

$$
e=\sqrt[3]{\left[1-\left(\frac{a}{b}\right)^{2}\right.}
$$

The mean bubble size ( Sauter mean diameter ) was then evaluated by [1]:

$$
d_{32}=\frac{\sum n d^{3}}{\sum n d^{2}}
$$

Table 1. Properties of surfactants

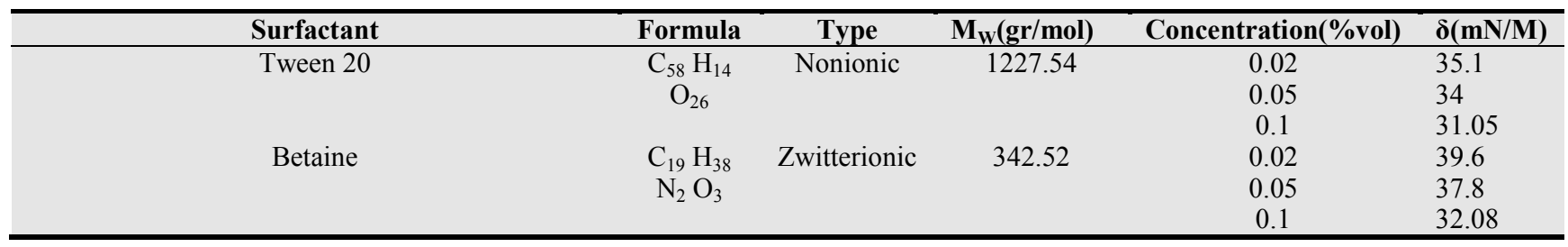

Where $n_{i}$ is the number of bubbles that have an equivalent diameter $(d i)$. The absolute error in $\mathrm{d}_{32}$ was estimated to be nearly $\pm 0.05 \mathrm{~mm}$. The overall gas hold-up was determined by visual measurements using the volume expansion method [9]. This was determined by measuring the difference between the un gassed and gassed liquid volumes. The gas hold-up was calculated from:

$$
\square_{g}=\frac{H-H}{H}
$$

Note that Eq. (3) and (4) is solved repeatedly at each superficial gas velocity and surfactant concentration using MATLAB software.

\section{Results and Discussion}

\section{1. Influence of Superficial Gas Velocity}

\section{1. 1. Bubble Size}

Regarding the influence of gas flow-rate upon the bubble diameter, different behaviors have been found; however, the commonest one indicates that an increase in the gas flow-rate produces a decrease in the bubble size. This behavior is in agreement with previous studies for other surfactant systems in bubble column [19]. Fig.3 and Fig.4 show the effect of gas flow rate upon bubble size at $\mathrm{C}_{\mathrm{s}}=0.02 \% \mathrm{vol}$ and surfactant + water systems as a function of bubble diameter. Increase in $u_{g}$ lead to higher liquid velocity, which can be responsible for the enhancement of turbulent intensity $[10,22]$ which in turn causes more bubble breakage and leads to a decrease in average bubble size and an increase in number of small bubbles. The mean bubble size increases with increasing superficial gas to $\mathrm{u}_{\mathrm{g}}=0.26 \mathrm{~cm} / \mathrm{s}$ (see Fig. 5). Initial increase in bubble diameter can be explained by an increase in dispersion of small bubbles within the system with increasing aeration rate and increasing the bubble collision frequency that lead to a higher coalescence rate and an increase in stable bubble diameter. Decrease in bubble size at velocity higher than $0.26 \mathrm{~cm} / \mathrm{s}$ can be attributed to increasing the proportion of bubble breakage (in agreement with photograph shown in Fig.2). At low superficial velocities, surfactant solutions have a mix of small and large bubbles with the larger bubbles being dominant. As superficial velocity increases, large bubbles disappear and small bubbles prevail.

However, the large bubbles are only observed at low superficial gas velocities. The size estimated from photography supported this observation. The values of $d_{32}$ obtained in this work are in the range of $0.3-0.6 \mathrm{~cm}$ which is in agreement with the experimental values reported by others $[7,12]$, as it can be observed in Figs5 and 10

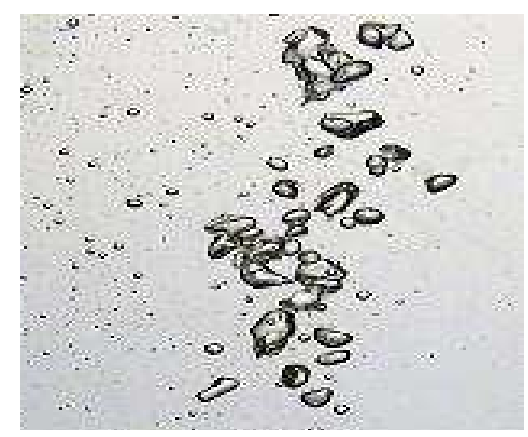

(a)

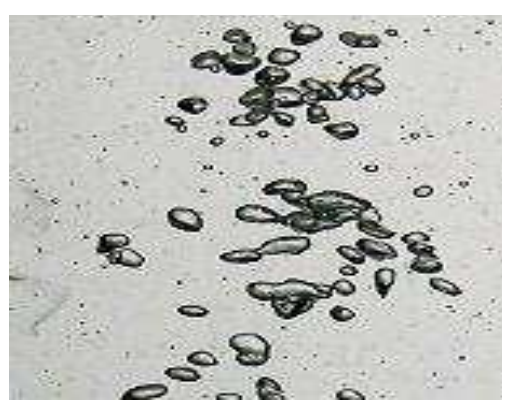

(b) 


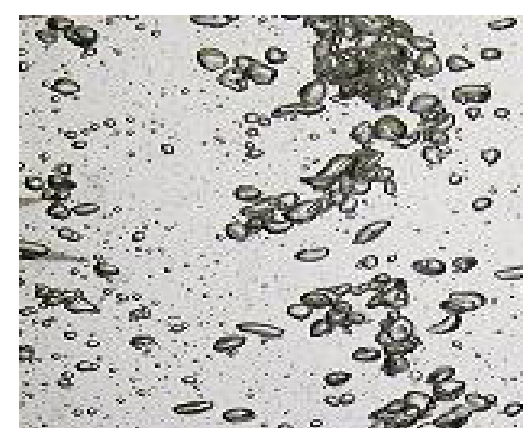

(c)

Fig2. Bubbles' photographs for Tween $20 /$ water system at $C_{s}=0.02 \% \mathrm{vol}$; (a) $u_{g}=0.13 \mathrm{~cm} / \mathrm{s}$; (b) $u_{g}=0.26 \mathrm{~cm} / \mathrm{s}$; (c) $u_{g}=0.5 \mathrm{~cm} / \mathrm{s}$

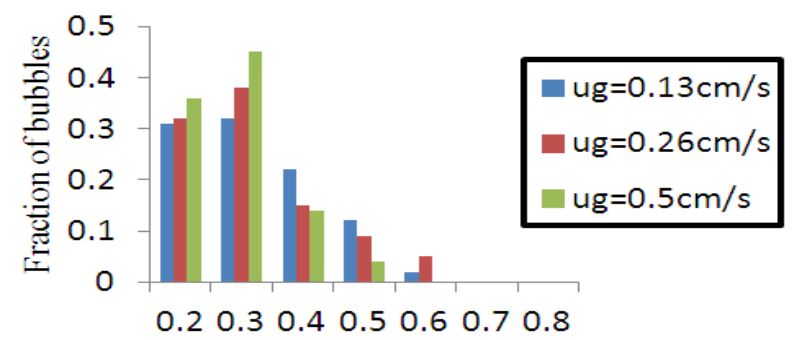

Bubble diameter $(\mathrm{cm})$

(a)

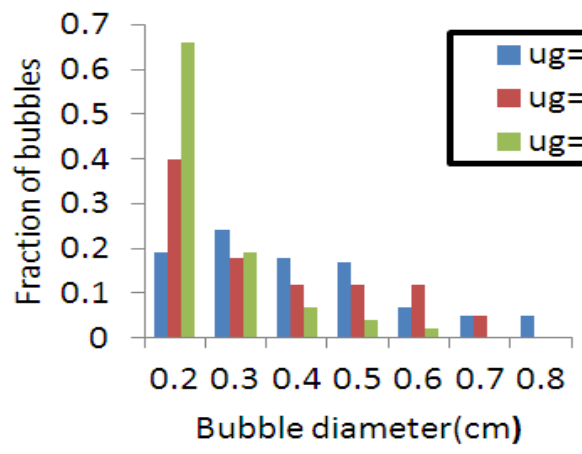

(b)

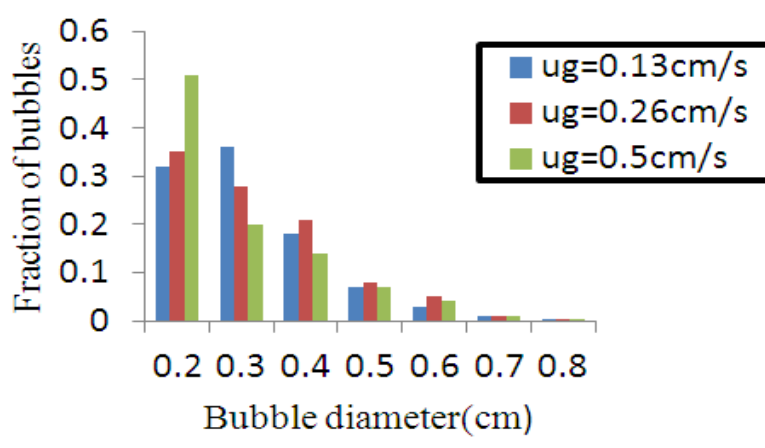

(c)

Fig 3. Influence of gas velocity upon bubble diameter in Betaine + water systems. $C_{s}=0.02 \%$ vol. (a) $h=5 \mathrm{~cm}$; (b) $h=20 \mathrm{~cm}$; (c) $h=40 \mathrm{~cm}$

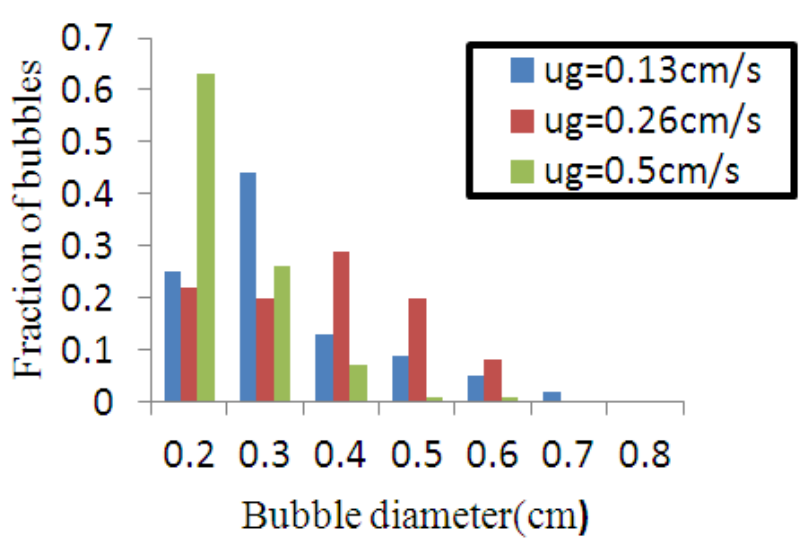

(a)

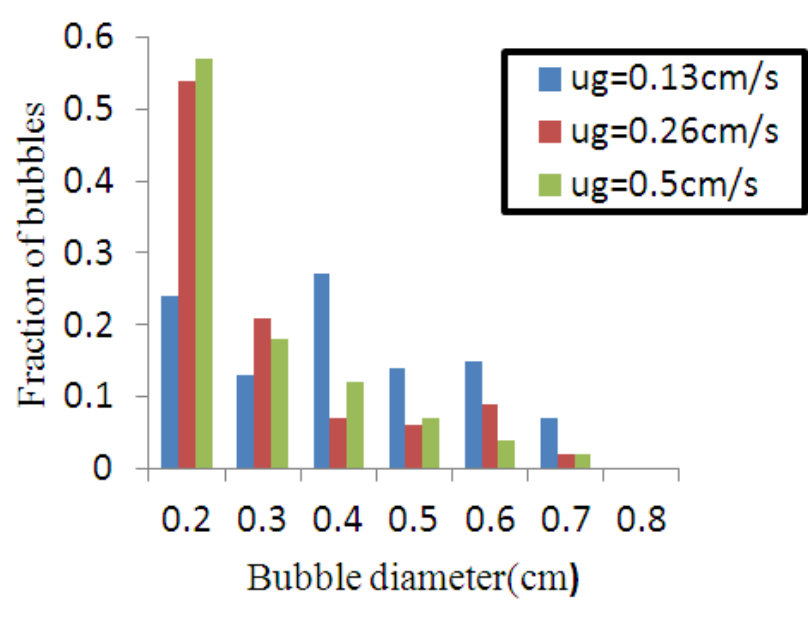

(b)

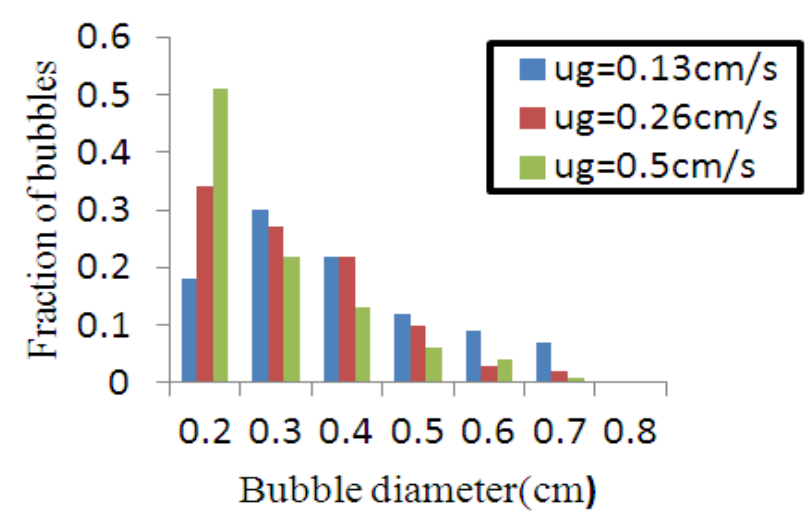

(c)

Fig 4. Influence of gas velocity upon bubble diameter in Tween $20+$ water systems. $C_{s}=0.02 \%$ vol. (a) $h=5 \mathrm{~cm}$; (b) $h=20 \mathrm{~cm}$; (c) $h=40 \mathrm{~cm}$ 


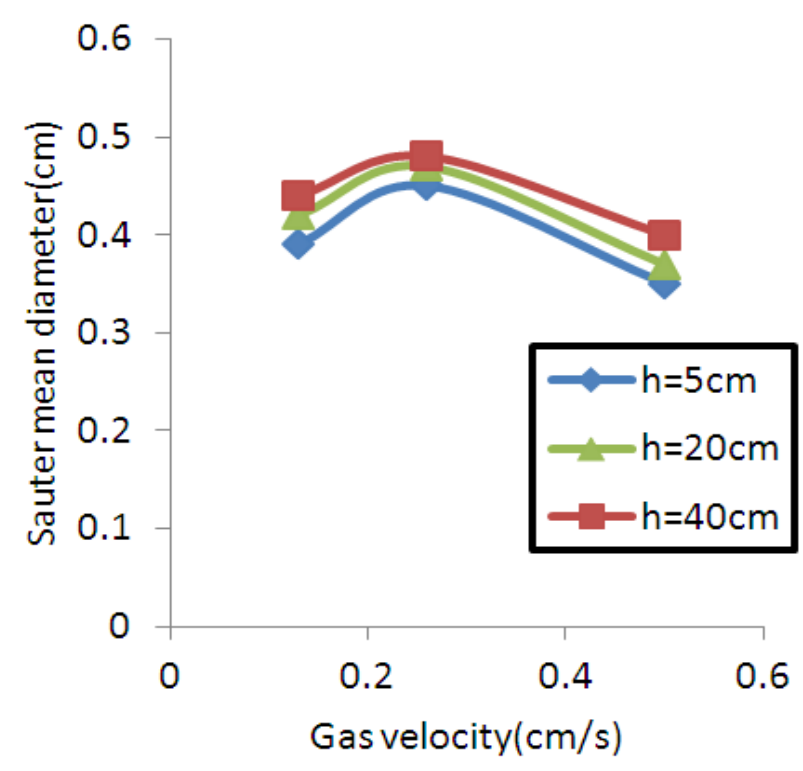

(a)

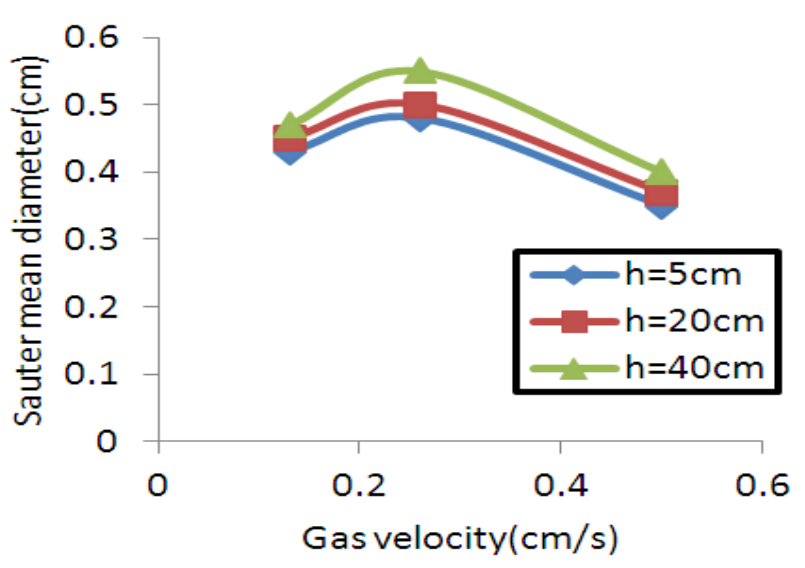

(b)

Fig 5. Effect of superficial gas velocity on Sauter mean bubble diameter at $C_{s}=0.02 \%$ vol. (a): Tween $20 /$ water (b): Betaine/water

\section{1. 2. Gas Hold-Up}

Fig. 6 showed the influence of superficial gas velocity on gas hold-up in surfactant solutions and also demonstrated that at low superficial gas velocities $\left(u_{g} \leq 0.5 \mathrm{~cm} / \mathrm{s}\right)$, addition of surfactant to water has a influence on the gas hold-up. Increasing the gas velocity increases the number of small bubbles with slower bubble rise velocities within the column, and thus increases the gas hold-up of the system [6]. On the other hand, a high $u_{g}$ increases the bubble collision frequency which leads to a higher coalescence with correspondingly larger bubbles [6]. The preferential release of larger bubbles may result in greater proportion of smaller bubbles in the fluid and consequently, a larger gas hold-up[6]. The molecular weight and surface tension decreased the bubbles diameter while increasing the hold- up (compared with pure water). The gas hold-up increased as following:

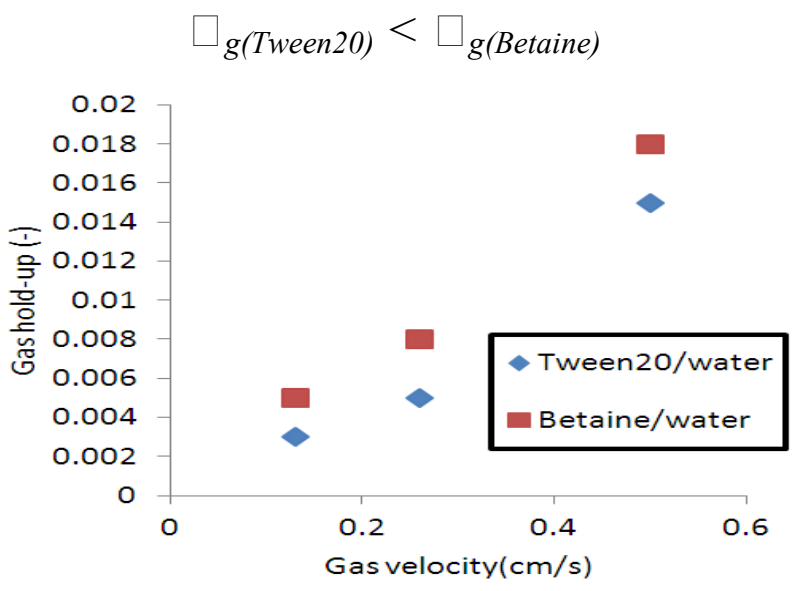

Fig 6. Effect of superficial gas velocity on gas hold-up at $C_{s}=0.02 \% \mathrm{ol}$

\section{2. Influence of Surfactant Concentration}

\section{2. 1. Bubble Size}

Fig. 9 shows photographs of bubbles which were used to analyse the influence of the betaine concentration on the bubble size and important changes have also been observed, concretely Fig. 9 shows that an increase in the surfactant concentration leads to clear decrease in the bubble diameter. The experimental results showed that an increase in the surfactant concentration causes also an increase in liquid phase viscosity. The solution of surfactant produces a decrease in surface tension and this behavior produces a decrease in bubble size and an increase in number of bubbles(see Fig. 7 and 8). Fig. 10 shows the influence of surfactant concentration upon the Sauter mean diameter. A decrease is produced in $\mathrm{d}_{32}$ with high surfactant concentrations, due to the existence of bubble rupture processes caused by the large size of the bubbles, the high liquid phase viscosity and the bubbles collisions.

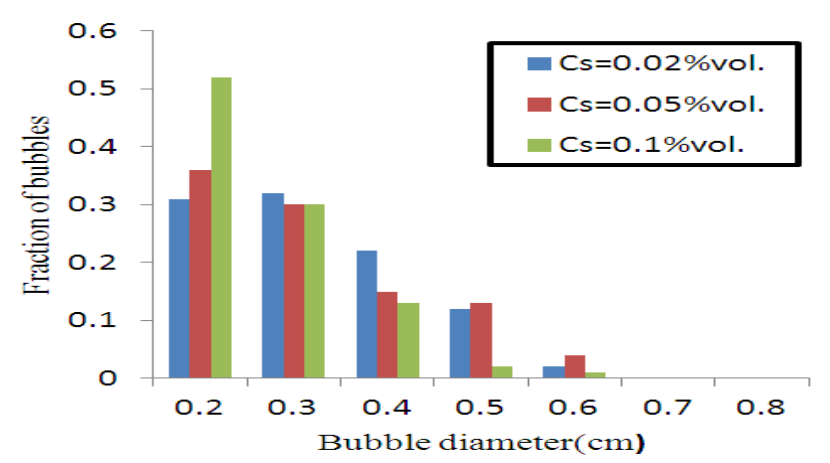

(a) 


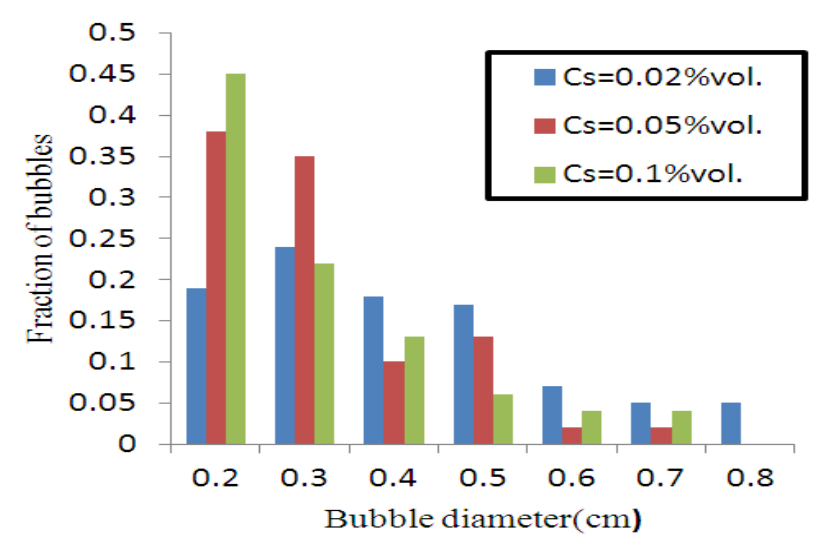

(b)

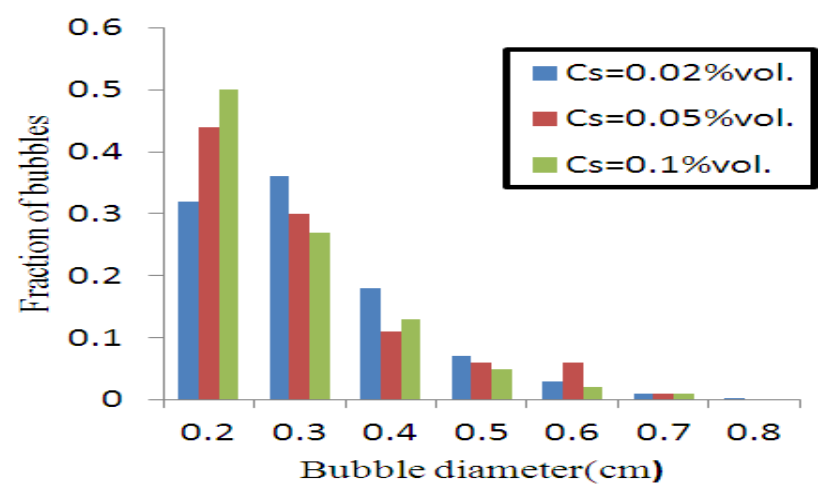

(c)

Fig 7. Influence of surfactant concentration upon bubble size in Betaine + water systems at $u_{g}=0.13 \mathrm{~cm} / \mathrm{s}$. (a) $h=5 \mathrm{~cm} ;(\mathrm{b}) \mathrm{h}=20 \mathrm{~cm} ;(\mathrm{c}) \mathrm{h}=40 \mathrm{~cm}$

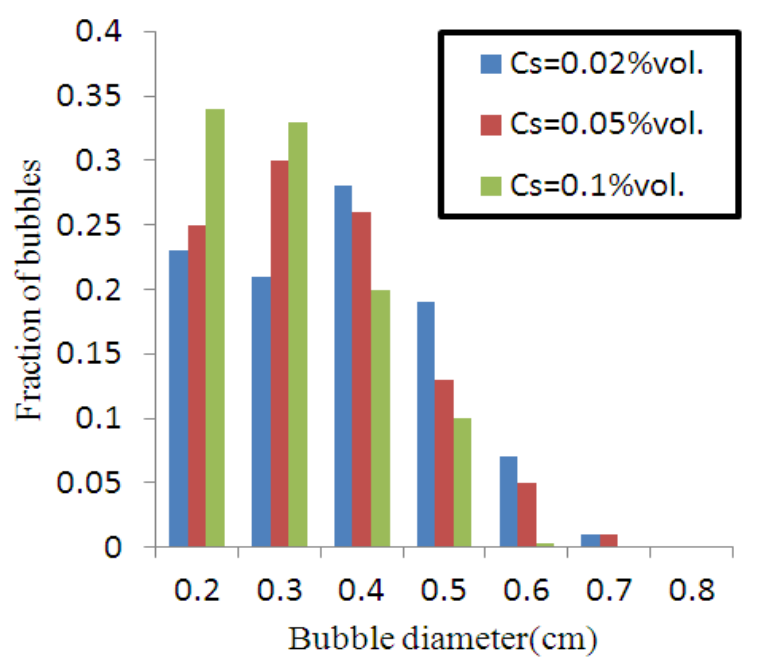

(a)

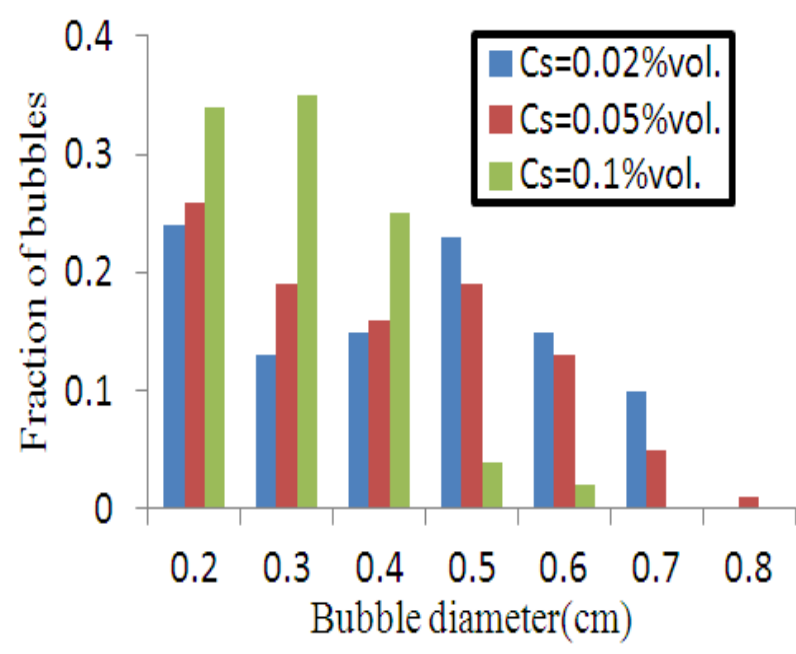

(b)

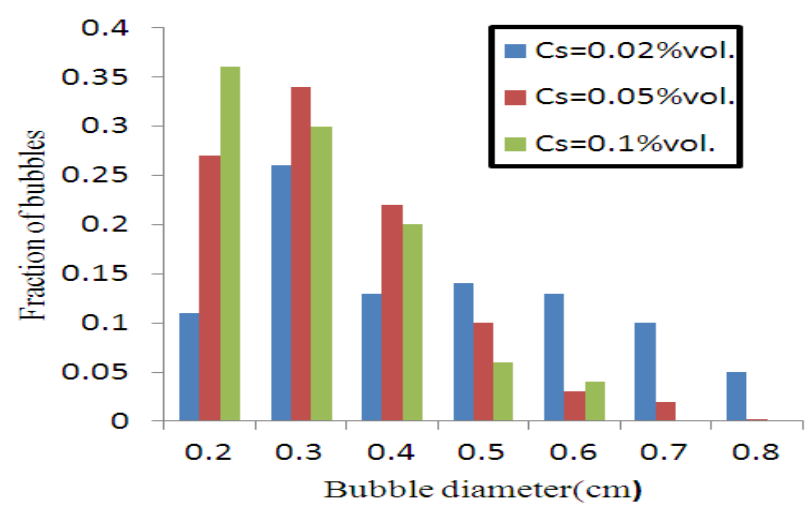

(c)

Fig 8. Influence of surfactant concentration upon bubble size in Tween 20 + water systems at $u_{g}=0.13 \mathrm{~cm} / \mathrm{s}$. (a) $h=5 \mathrm{~cm}$; (b) $h=20 \mathrm{~cm} ;(\mathrm{c}) h=40 \mathrm{~cm}$.

\section{2. 2. Gas Hold-Up}

Fig. 11 illustrates the influence of surfactant concentration on gas hold-up at $\mathrm{u}_{\mathrm{g}}=0.13 \mathrm{~cm} / \mathrm{s}$. According to Fig. 11, the gas hold-up increases moderately with the increasing of the surfactant concentration, especially at higher concentration. The rise velocity of bubbles decreases by increasing the surfactant concentration. This decrease can be attributed mainly to a proportional rise in the concentration of surfactant in water and a decrease of surface tension with increasing surfactant concentration [6]. Also, increasing the surfactant concentration produces smaller bubbles and increases viscosity which in turn increases the gas hold-up[14]. When low surfactant concentration is present in the liquid phase, an important decrease in gas hold-up is observed. However, a higher surfactant concentration produces the opposite behavior that gas hold-up increases. Depending on the type of surfactants, gas hold-up in betaine solution was more than tween20/water system and return to affect molecular weight in gas hold-up. 


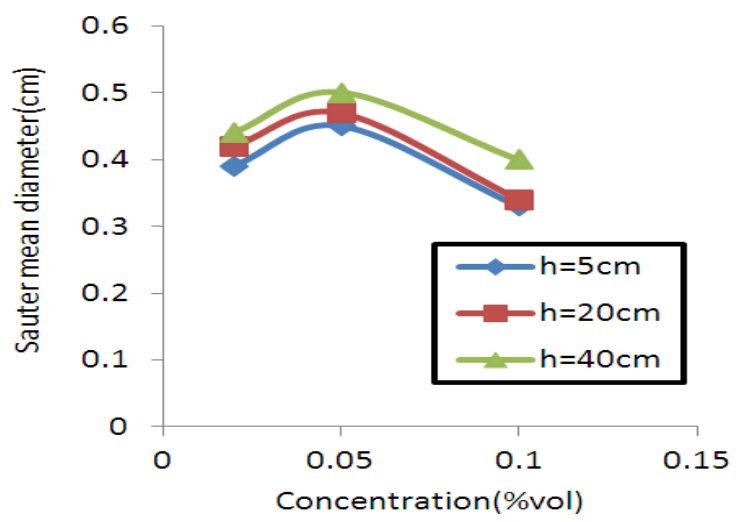

(a)

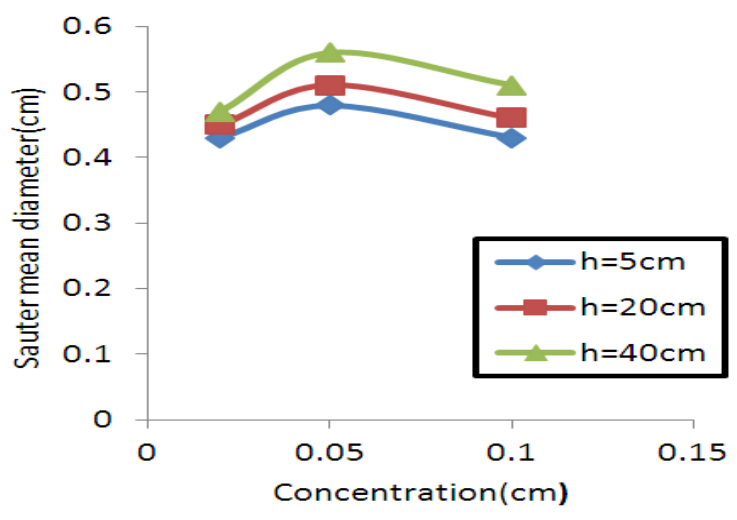

(b)

Fig 10. Influence of surfactant concentration upon Sauter mean bubble diameter at $u_{g}=0.13 \mathrm{~cm} / \mathrm{s}$. (a):Tween $20 /$ water (b): Betaine $/$ water

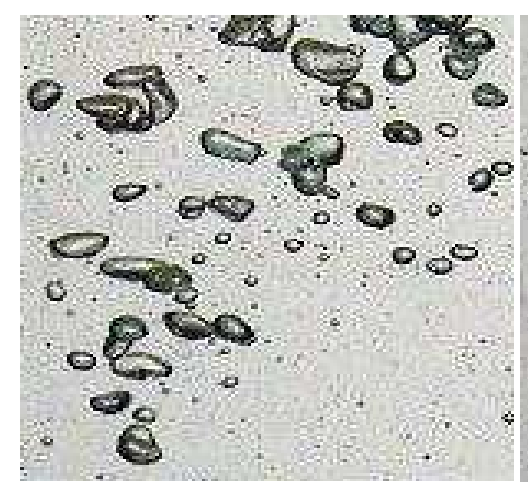

(a)

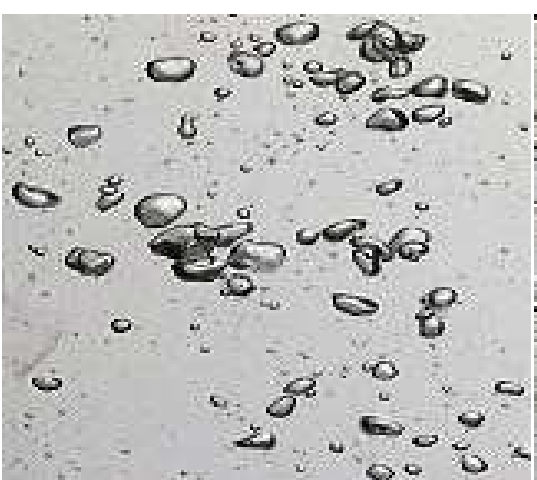

(b)

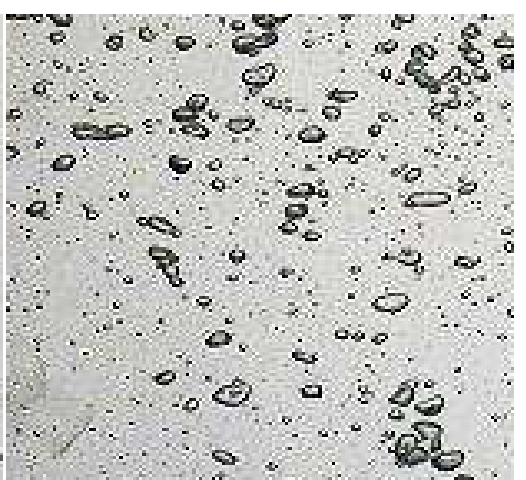

(c)

Fi. 9. Influence of betaine concentration upon bubble size in Betaine + water systems. $u_{g}=0.13 \mathrm{~cm} / \mathrm{s},(\mathrm{a}) C_{s}=0.02 \% \mathrm{vol} ;\left(\right.$ b) $C_{s}=0.05 \% \mathrm{vol}$; (c) $C_{s}=0.1 \% \mathrm{vol}$

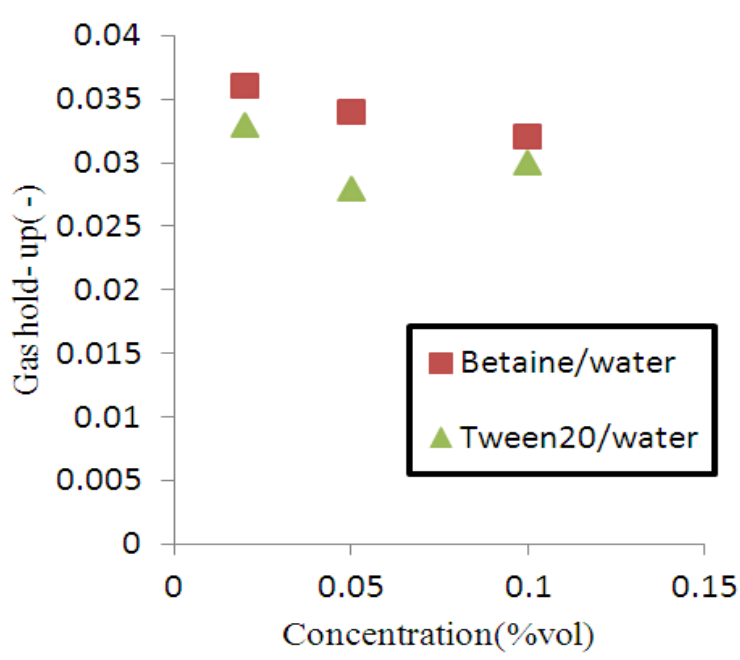

Fig 11. Influence of surfactant concentration upon gas hold-up at $u_{g}=0.13 \mathrm{~cm} / \mathrm{s}$

\section{Conclusion}

Presence surfactant has a profound influence on bubble size and gas hold-up. When gas flow increases to $0.26 \mathrm{~cm} / \mathrm{s}$, superficial gas velocity has low influence on bubble size but at higher superficial gas velocity, adding a surfactant reduce bubble size. Superficial gas velocity and surfactant concentration has a high influence on a of small bubble. Increase in concentration of surfactant results in increasing number of bubbles and gas hold-up and decreasing $\mathrm{d} 32$, which can be attributed to increasing the coalescenceinhibiting tendency and decreasing of surface tension. The Sauter mean diameter decreases with increasing of gas velocity. Large bubble size disappearance at high velocities maybe because of bubble breaks up due to turbulence. Superficial gas velocity has high influence upon bubble coalescence. The surfactant addition increased the gas hold-up (at highest gas flow rate and surfactant concentration). The gas hold-up effect in the surfactant solutions depends on the molecular weight, surface tension and surfactant type. 


\section{Nomenclature}

$u_{g} \quad$ superficial gas velocity $(\mathrm{m} / \mathrm{s})$

$C_{s} \quad$ surfactant concentration

a major axis of the projected (m)

$b \quad$ minor axis of the projected ellipsoid (m)

$h$ distance from gas distributor(m)

$d_{32}$ sautor mean diameter bubble(m)

$d \quad$ diameter(m)

$e \quad$ bubble eccentricity

$H_{0} \quad$ ungassed column height (m)

$H$ column dispersion height due to the presence of gas bubbles (m)

\section{Greek letters}

$\square_{g} \quad$ gas hold-up

\section{References}

[1] Akita, K., Yoshida, F., 1973, Gas Holdup and Volumetric Mass Transfer Coefficient in Bubble Column. Effect of Liquid Properties, Ind Eng Chem Process Res,12,76-80.

[2] Akita, K., Yoshida, F., 1974. Bubble size, interfacial area and liquid-phase mass transfer coefficient in bubble columns. Ind Eng Chem Process, 12, 76-80.

[3] Al-Masry, W. A., Ali, E. M., 2007. Identification of hydrodynamics characteristics in bubble columns through analysis of acoustic sound measurements-Influence of the liquid phase properties. Chem Eng Processing 46, 127-138.

[4] Al-Masry, W. A., Ali, E. M., Aqeel, Y. M., 2005. Determination of bubble characteristics in bubble columns using statistical analysis of acoustic sound measurements. Chem Eng Research and Design 83, 1196-1207.

[5] Anastasiou, A. D., Kazakis, N. A., Mouza, A. A., Paras, S. V., 2010. Effect of organic surfactant additives on gas holdup in the pseudo-homogeneous regime in bubble columns equipped with fine pore sparger. Chem Eng Sci, $65,5872-5880$.

[6] Asgharpour, M., Mehrnia, M. R., Mostoufi, N., 2010. Effect of surface contaminants on oxygen transfer in bubble column reactors. Biochem Eng Jour, 49, 351-360.

[7] Boauifi, M., Hebrard, G., Bastoul, D., Roustan, M., 2001. A comparative study of gas hold-up, bubble size, interfacial area and mass transfer coefficients in stirred gas-liquid reactor and bubble columns. Chem. Eng. Process. 40, 97111.

[8] Cachaza, E.M., Di'az, M.E., Montes, F.J., and M.A. Gala'n, M.A., 2009. Simultaneous computational fluid dynamics (CFD) simulation of the hydrodynamics and mass transfer in a partially aerated bubble column. Industrial and Engineering Chemistry Res., 48(18): 8685-869.

[9] Chisti, Y., Moo-Young, M., 1988, Hydrodynamics and oxygen mass transfer in a pneumatic bioreactor devices, Biotechnol. Bioeng. 3, 1487-1494.
[10] Choi, K. H., Lee, W. K., 1993. Circulation liquid velocity, gas holdup and volumetric oxygen transfer coefficient in external-loop airlift reactors., J. Chem. Tech. Biotechnol. $56,51-58$.

[11] Deckwer, W.D., 1992. Bubble Column Reactors. Wiley, Chichester.

[12] Garcia, A, A., Diaz, G., Navaza, J. M., Sanjurjo, B., 2010. Effect of surfactant nature upon absorption in a bubble column. Chem Eng Sci, 65, 4484-4490.

[13] Garcia, A, A., Diaz, G., Navaza, J. M., Vidal-Tato, I., 2011. Hydrodynamics of a carbom dioxide/water/silicone oil bubble column. Chem Eng Jour, 171, 1108-1113.

[14] Garcia-Abuin, A., Gomez-Diaz, D., Losada, M., Navaza, J. M., 2012. Bubble column gas-liquid interfacial area in a polymer + surfactant + water system. Chem Eng Sci, 75, 334-341.

[15] Joshi, J.B., Parasu Veera, U., Prasad, C.V., Phanikumar, D.V., Deshphande, N.S., Thakre, S.S., Thorat, B.N., 1998. Gas hold-up structure in bubble column reactors. PINSA 64A (4), 441-567.

[16] Kalekar, M.S., Bhagwat, S, S., 2006. Dynamic behavior of surfactants in solution. Journal of Dispersion Sci and Technol., 27(7): 1027-1034.

[17] Kothekar, S.H.C., Ware, A.M., Waghmare, J.T., Momin, S.A., 2007. Comparative analysis of the properties of Tween-20, Tween-60, Tween-80, Arlacel60 and Arlacel-80. Journal of Dispersion Sci and Technol., 28(3): 477-484.

[18] Krishna, R., VanBaten, J.M., 2003. Mass transfer in bubble columns. Catal Today, 79-80,67-75.

[19] Kulkarni, A. A., Joshi, J. B., 2005. Bubble formation and bubble rise velocity in gas-liquid system: a review. Ind. Eng. Chem. Res. 44, 5873-5931.

[20] Nigar, K., Fahir, B., Kutlu, O. U., 2005. Bubble column reactors: A review. Process Biochemistry 40, 2263-2283.

[21] Porter, M.R., 1994. Hand book of Surfactants, Blackie, London.

[22] Prince,M. J., Blanch, H. W., 1990. Bubble coalescence and break-up in air-sparged bubble column. AIChE. 36, 14851499.

[23] Ribeiro, C.P., Lage, P.L.C., 2005. Gas-liquid direct-contact evaporation: a review. Chem Eng \& Tech, 28 (10), 10811107.

[24] Ruzicka, M. C., Vecer, M. M., Orvalho, S., Drahoš, J., 2008, Effect of surfactant on homogeneous regime stability in bubble column, Chem Eng Sci, 63 ,951-967.

[25] Sardeing, R., Painmanakul, P., Hébrard. G., 2006. Effect of surfactants on liquid-side mass transfer coefficients in gasliquid systems: A first step to modeling. Chem Eng Sci., 61(19): 6249-6260.

[26] Shaw, D., 1992. Surface activity and micelle formation. Modified by T. Corcoran.

[27] Yang, Y.M., Maa, J.R., 1984, Bubble coalescence in dilute surfactant solution. Journal of Colloid and Interface Sci 98, $120-125$. 
[28] Zaruba, A., Krepper, E., Prasser, H. M., Schleicher, E., 2005, Measurment of Bubble Velocity Profiles and Turbulent Diffusion Coefficients of the Gases Phase in Rectangular
Bubble Column Using Image Processing, Experimental Thermal and Fluid Sci ,29,851-860. 